\title{
Domestic Factors That Affect the Price of Styrene Butadiene Latex in Indonesia
}

\author{
Rosalendro Eddy Nugroho \\ Post Graduate School of Management, Post Graduate Faculty, Universitas Mercu Buana-Indonesia \\ Corresponding Author: rosalendro.eddy@mercubuana.ac.id
}

Recieved: November 2018 | Revised: January 2019 | Accepted: February 2019

\begin{abstract}
This paper investigates or examines the causal links between price of styrene butadiene latex (SBL) and other domestic variables such as supply, demand, Herfindahl Hirschman Index (HHI), price of styrene, and price of butadiene during the period of 1995-2017 on the monthly basis.. Results from Augmented Dickey Fuller (ADF) or unit root test showed that the stationary state of the whole variables is of first difference (I). The Granger pairwise causality test revealed a bidirectional causality of SBL with BTD(Butadiene), SBL with STY(Styrene), SUPP(Supply) with DMD(Demand), DMD with STY, DMD with BTD and STY with SUPP and vice versa. Johansen test found out a co-integration of SBL prices. However, this study proved no significant links between the price of SBL and supply of SBL (SUPP) in the long and short run. This paper highlights the fact that SBL price has a significant direct impact in the long run on the styrene (STY) and butadiene (BTD) prices, as well as HHI. Similarly, these aspects also have a significant direct impact proved by the positive coefficient in the long run on the SBL pricing. The findings further showed that the price of SBL has a connection and significant direct impact on the negative arrow for the short and long run equilibrium, in line with the price and demands for SB Latex, pressing and oil classification.
\end{abstract}

Keywords: Co-integration, Granger Causality, Supply, SBL and HHI.

JEL Classification: E30

How to Cite: Nugroho, R. (2019). Domestic Factors That Affect The Price of Styrene Butadiene Latex in Indonesia. Jurnal Ekonomi Pembangunan: Kajian Masalah Ekonomi dan Pembangunan, 20(1). doi:https://doi.org/10.23917/jep.v20i1.7097

DOI: https://doi.org/10.23917/jep.v20i1.7097

\section{Introduction}

Petrochemical product derivatives, namely SB Latex, can generally be affected by the increase in crude oil prices in the global market, because if crude oil or crude oil increases, it will indirectly increase the prices of the main raw materials, namely styrene prices and butadiene prices (Fan, 1998). Styrene Butadiene Latex (SB latex) industry is one of the petrochemical industry products that are still the mainstay of Indonesia in providing the main raw material for paper coating industry and carpet backing. Therefore, the ups and downs of production supply depend on the demand for coating paper. SB latex industry in Indonesia is an industrial intermediate for the paper industry and carpet (E.H. Pechan \& Associates, 1995).

The petrochemical industry is inseparable from external factors that can affect the sustainability of the industry in the future, this factor is the oil price shock, the results of empirical research show that the volatility of world crude oil prices has a dominant positive effect on derivative prices product (SB Latex) petrochemical (Zhang, 2011). In line with the growing development of paper industry in the 
Jurnal Ekonomi Pembangunan: Kajian Masalah Ekonomi dan Pembangunan, 20 (1), 2019, 60-68

last five years, it encourages the increase of economic growth as well, which results in the boosting demand for SB Latex in Indonesia. SB latex industry is a special chemical industry that since 1991 SB latex industry in Indonesia has only been run by a few multinational companies (PT BASF, Dow Chemical PT and PT Latexia). These companies highly dominate the technology as well as capital support, so that the structures and properties of SB latex industry in Indonesia is oligopoly (Mei \& Sun, 2008).

Value SB Latex industry generally cannot be separated from and is dependent on the availability of raw materials. The main raw materials in SB Styrene and Butadiene Latex production are Styrene and Butadiene, whose prices become the largest determiner in the pricing of SB Latex in Indonesia, nearly 90\% (Nugroho, Hakim, Nurmalina, \& Manurung, 2011) .

This SB Latex prices fluctuate greatly, constantly being influenced by the demand of dominant domestic markets, namely PT Indah Kiat, PT Tjiwi Kimia, PT Pindo Deli, PT Universal, and PT Indonesian Nobel Carpets. Besides, there is also a competition among the three SB Latex producers in Indonesia. Butadiene until now has never been produced in Indonesia. For more than fifteen years, the use of the butadiene in the domestic industry can be met through imports ( Nugroho, Albar, \& Hasibuan, 2018).

\section{Research Method}

According to the results of research conducted by Luburic and Katz (2011), the petrochemical industry to be able to survive and compete competitively must be able to meet the criteria and advantages that consist of; production, shipping, cost efficiency, mergers \& acquisitions, simplifying production systems or sustainable technology development, strategic locations, and integrated factories from upstream to downstream industries.

The control and saving of raw material costs is absolutely necessary in the petrochemical industry, considering that the petrokima industry is inseparable from fluctuations and higher prices of world crude oil. Because the raw material for SB Latex petrochemical products is derived from the oil processing industry and upstream petrochemical industries such as styrene, butadiene, acrylic acid, so that the effect multiplier will occur in this event (jorgenson, 1968)

The data in this study were secondary data taken from time-series data, which were monthly data from the period of January 1995 until December 2015.These data include the price of SB Latex in Indonesia (SBL), which is the average price from the three producers in Indonesia, namely PT BASF, PT Dow Chemical and PT Latexia. Besides, the data also consist of SB Latex production capacity in Indonesia from the three SB Latex manufacturers (SUPP: Supply), SB Latex level of demand from industrial users of SB Latex (DMD: Demand), the main raw material prices that are the prices of Styrene (STY: Styrene) and Butadiene (BTD: Butadiene), as well as market share or SBL industrial structure in Indonesia (HHI: Herfindal Hirschman Index) and OIL (Global Oil Price). The Whole data is taken from PT BASF Indonesia, PT Dow Chemical, Federal Reserve Bank and Carpicorn Indo Consultant (CIC).

\subsection{Empirical Model}

Data The existence of cointegration approach is performed using the method of Johansen or Engel-Granger. If the variables are not cointegrated, we can apply the standard VAR results that will be identical to the OLS (Ordinary Least Square). This is carried out after ensuring that the variables have been stationary on the same the degree (order). If there are cointegration vectors in verification testing, they will be applied to a single equation of ECM or VECM for the system equation.

The derivation of error correction model (VECM) vector is based on the theorem by Johansen, (1990); Usman and Aliyu (2009). Suppose $\{\mathrm{Z}\}$ is a degree of VAR to-p and $\mathrm{Zt}=\{\mathrm{Y}$ : $\mathrm{X}$, where $\mathrm{Y}$ is the variable of Endogenous and $\mathrm{X}$ is the variable of Exogenous. It can be expressed 
as follows:

$\sum_{i=1}^{n} Z_{t}=p \prod Z_{t}-1+\Psi_{y} \mathcal{W}_{t}+\delta_{o}+\epsilon_{t}$

where:

ry. $\epsilon_{t}=$ Gaussian Error Term.

$\mathcal{W}_{t} \quad=$ vector of variables are stationary

One vector $\mathrm{Zt}$ has error correction

representation if it can be expressed as follows:

$\sum_{i=1}^{n} \Delta Z_{t}=p \Pi \Delta Z_{t}-1+\sum_{i=1}^{p-1} \Pi_{t}+\Psi_{y} w_{t}+\delta_{0}+\varepsilon_{t}$

where:

$\Pi_{i}=-\Pi+\Pi_{1}+\cdots \Pi_{i},(i=1,2, \ldots . p-1)$

$\Pi_{i}=-\left[\Pi+\Pi_{1}-\Pi_{p}\right]=\alpha \beta^{\prime}$

There are two ways to solve the regression equation: First, provides a unified maximum likelihood procedure in which $a$ and $B$ obtained from the decomposition of the matrix $\Pi$. Both
Engle and Granger (1987) proposed a two-step estimation using cointegration regression, so that B Zt-1, residual estimation (estimated residue) is included in the regression equation above. This study will adopt the Johansen procedure.

One restriction that will be incorporated into the model estimates the VEC on the long-term coefficient (B). The theoretical model shows that $B$ is not full rank matrix. Due to the small sample size, inclusion of all the variables lagged first difference in each VEC equation, which will reduce significantly the degree of freedom. Therefore, to overcome these problems, the procedure to follow is as suggested by Usman and Aliyu (2009). The model will be divided into several blocks, and then the variables included in the model are based on theoretical models. Based on the division, six blocks are then formed in the VEC SBL, VEC SUPP, VEC DMD, VEC HHI, VEC OIL, VEC STY and VEC BTD., so the Error Correction Model equation model can be written as follows:

$$
\left[\begin{array}{c}
\Delta S B L \\
\Delta S U P P \\
\Delta D M D \\
\Delta H H I \\
\Delta S T Y \\
\Delta B T D
\end{array}\right]=\left[\begin{array}{l}
\alpha_{10} \\
\alpha_{20} \\
\alpha_{30} \\
\alpha_{40} \\
\alpha_{50} \\
\alpha_{60}
\end{array}\right]+\left[\begin{array}{l}
a_{11} L a_{12} L a_{13} L a_{14} L a_{15} L a_{16} L \\
a_{21} L a_{22} L a_{23} L a_{24} L a_{25} L a_{26} L \\
a_{31} L a_{32} L a_{33} L a_{34} L a_{35} L a_{36} L \\
a_{41} L a_{42} L a_{43} L a_{44} L a_{45} L a_{46} L \\
a_{51} L a_{52} L a_{53} L a_{54} L a_{55} L a_{56} L \\
a_{61} L a_{62} L a_{63} L a_{64} L a_{65} L a_{66} L
\end{array}\right]\left[\begin{array}{c}
\Delta S B L \\
\Delta S U P P \\
\Delta D M D \\
\Delta H H I \\
\Delta S T Y \\
\Delta B T D
\end{array}\right]+\left[\begin{array}{l}
\epsilon_{1 t} \\
\epsilon_{2 t} \\
\epsilon_{3 t} \\
\epsilon_{4 t} \\
\epsilon_{5 t} \\
\epsilon_{6 t}
\end{array}\right]
$$

where $\mathrm{L}$ is Operating $\mathrm{Lag}\left(\mathrm{LZ}=\mathrm{Z}_{\mathrm{t}-1}\right)$, ano is a vector ( $\mathrm{nx} 1)$ intercept, am $\mathrm{xn}$ is the coefficient matrix (mxn), en xt is the coefficient of the error correction (error correction term), and $\Delta$ is the first difference order used to reduce stationary variables.

Unlike other procedures, methods of dynamic equations proposed by Johansen integrate longterm and short-term relationships in one unit at a time. One is to look through the causal relationship between the dependent variables, between the dependent variables and independent variables, and between the independent variablesat the optimum lag (to see the short-term connections) and through relations of causality additional error correction (error correction channel), to see the long-term and short-term relationships.

\section{Result}

\subsection{Unit Root Tests}

Augmented Dickey-Fuller Test is used to examine the unit root (Unit Root Test) in terms of the stationary states of variable price of SB latex (SBL), SB Latex production capacity in Indonesia (SUPP), the level of demand SB Latex by the user (DMD), a market segment producer SB Latex 
in Indonesia (HHI), the price of the main raw materials styrene (STY) and butadiene (BTD). To include trend and intercept, with provisions, the tested hypothesis is Ho: $B 1=0$ (indicating the presence of unit root test and no stationary state) and $\mathrm{H} 1: B 1 \neq 0$ (indicating the absence of unit root and the presence of stationary state). Here, $B 1$ is the value of the ADF. If the absolute value of the $A D F$ is greater than the critical value of $\mathrm{HO}$ hypothesis, and if it states that the data containing unit root are rejected, it means the time-series data are not stationary. Likewise, if the absolute value of the ADF is smaller than the critical value of HO hypothesis, stating the data are accepted, it can be concluded that the timeseries data are stationary unit root or data. Unit root test results are as follows:

Table 1. Root Test Results on the First Difference

\begin{tabular}{lcccc}
\hline t- statistic & SBL & SUPP & DMD & STY \\
\hline $\begin{array}{l}\text { Critical } \\
\text { Values }\end{array}$ & (Trend) & (Trend) & (Trend) & (Trend) \\
$t$-Statistics & -11.8024 & -14.3146 & -11.0335 & -16.5005 \\
$($ ADF) & & & & \\
Critical & -2.8759 & -2.8758 & -2.8759 & -2.8757 \\
Values 5\% & & & & \\
\hline
\end{tabular}

Source:Researcher's Analysis Using Eview Program

To make sure that the data are stationary, the unit root test in the first difference of data needs to be carried out. Test results using the ADF test shown in Table 1 indicate that all endogenous variables or variables of the study have been stationary at the $5 \%$ significance level. This means that all the variables are above stationary in the first difference, thus it can be said that variables are integrated on the degree of one or I.

\subsection{VAR Stability Test}

The next step is to conduct the VAR stability test or VAR stability condition check. If all the roots of the polynomial function are inside the unit circle or if the absolute value is smaller than one, the VAR model is considered stable. VAR stability test results are as follow.

Table 2. VAR Stability Test Results

\begin{tabular}{cc}
\hline Root & Modulus \\
\hline 1.001168 & 1.001168 \\
$\mathbf{0 . 4 2 2 2 0 8}$ & $\mathbf{0 . 4 2 2 2 0 8}$ \\
\hline
\end{tabular}

Source:Researcher's Analysis Using Eview Program

From the data in Table 2, SBL, SUPP and DMD, STY, BTD, and HHI, the whole root and modulus are 0.42208 (less than one/1). None of its roots lies outside the unit circle, so that the VAR model is proven to be in a stable condition.

\subsection{Optimum Lag Test}

An important step that must be done in the VAR-VECM model is the determination of the optimal number of lag used in the model. Testing the optimal lag length requires some information that is provided through the Akaike Information Criterion (AIC), Scharwz Criterion (SC) and Hannan-Quinn Criterion (HQ). The results are as follows:

Table 3. Test Results to Obtain Optimum Lag

\begin{tabular}{cccccc}
\hline Lag & LogL & LR & FPE & AIC & SC \\
\hline 0 & -9082.818 & NA & $7.64 \mathrm{e}+32$ & 92.7430 & 92.8434 \\
$\mathbf{1}$ & -8201.613 & 1699.468 & $\mathbf{1 . 3 7 e + 2 9 *}$ & $\mathbf{8 4 . 1 2 *}$ & $\mathbf{8 4 . 8 *}$ \\
8 & -7993.99 & $\mathbf{6 6 . 9 *}$ & $2.30 \mathrm{e}+29$ & 84.5713 & 89.4885 \\
\hline
\end{tabular}

Source:Researcher's Analysis Using Eview Program

The result of the analysis in the Table 3 shows that the value of the SIC at the smallest lag is 1. Therefore, for the next test, using 1 as the Lag Optimum value, the selection criteria use traditional Scharwz Information Criterion (SIC). Obtaining the SC, if goes well, brings in the selection of optimal lag. This serves as the basic instructions of the next test.

\subsection{Granger Causality Test}

Granger causality test aims to determine the causal relationships between variables. The core of this test can indicate whether a variable has a two-way or one-way, or no connection. This test 
is seen as the influence of the past on the present condition (Wen, 2007)]. The results of Granger causality test are as follows:

Table 4. Test Results of Granger Casuality in

\begin{tabular}{ccccc}
\multicolumn{5}{c}{ Pairwise } \\
\hline $6 \times 6$ & SBL & SUPP & DMD & HHI \\
\hline SBL & & & & \\
SUPP & $\rightarrow$ & & & \\
DMD & $\rightarrow$ & $\leftrightarrow$ & & \\
HHI & $\rightarrow$ & $\neq$ & $\neq$ & \\
STY & $\leftrightarrow$ & $\leftrightarrow$ & $\leftrightarrow$ & $\neq$ \\
\hline
\end{tabular}

Description: $\leftrightarrow$ Significant two-way. $\rightarrow \leftarrow$ Significant

$$
\text { one-way. } \neq \text { Not }
$$

Source:Researcher's Analysis Using Eview Program.

Testing in pairs (pairwise) in Table 4 was carried out by using the Granger Causality Test. The level of significance (a) $5 \%$ showed significant results in endogenous variable (SBL, SUPP, DMD, HHI, STY and BTD). The total test of six Endogenous variables yielded fifteen pairs of variables that influence each other. Six pairs of variables affect each other or have bilateral bidirectional causality (SBL with STY, SBL with BTD, SUPP with DMD, DMD with STY, DMD with BTD, and STY with SUPP). Four pairs of variables do not affect each other, Not having two-way connection or independence (SUPP with HHI, DMD with HHI,STY with HHI and SUPP with BTD). Meanwhile, the remaining five pairs of variables have opposite properties, namely one direction or directional interplay. Therefore, a total of sixty percent of endogenous variables affect each other.

\subsection{Cointegration Test}

Verbeek (2008) argued that the existence of a cointegration relationship in a system of equations implies that there is an error correction model that illustrates the consistency of shortterm dynamics with the long-term relationship. In other words, cointegration presented a long-term equilibrium relationship. Cointegration test in this study uses Johansen approach by comparing the trace statistic with the critical value used, which is $5 \%$. If the trace statistic is greater than the critical value, it means that there is a cointegration in the equation. Cointegration test results are as follows:

Table 5. Test Results of Unrestricted Cointegration Rank (Trace)

\begin{tabular}{cccc}
\hline $\begin{array}{c}\text { Hypothesized } \\
\text { No. of CE(s) }\end{array}$ & Eigenvalue & $\begin{array}{c}\text { Trace } \\
\text { Statistic }\end{array}$ & $\begin{array}{c}\mathbf{0 . 0 5 ( 5 \% )} \\
\text { Critical } \\
\text { Value }\end{array}$ \\
\hline None $*$ & 0.245441 & $\mathbf{1 5 8 . 4 3 1 8}$ & 95.75366 \\
At most $\mathbf{1} *$ & 0.197870 & $\mathbf{1 0 1 . 5 4 4 3}$ & 69.81889 \\
At most $\mathbf{2} *$ & 0.136214 & $\mathbf{5 7 . 0 0 6 2 9}$ & 47.85613 \\
\hline
\end{tabular}

Source:Researcher's Analysis Using Eview Program

Based on the results of cointegration tests shown in Table 5, SB Latex pricing in Indonesia is determined by variable interplay, including production capacity (SUPP), SBL products by customer demand (DMD), the market share of the SBL (HHI) and the main raw material usage. Styrene Butadiene (STY and BTD) indicates no cointegration in the rank 3 to trace. With the cointegration, estimation results further using VECM models.

\subsection{VECM Estimation Results}

Cointegration test in the previous VECM system proves that there is a cointegration between variables involving SBL, SUPP, DMD, HHI, STY and BTD. Therefore, the SB Latex pricing responsiveness analysis of various microeconomic variables in this study is combined with the VECM models. The VECM models provide estimations of the two main outputs (Jones, Leiby, \& Paik, 2004) that measure the cointegration or longterm equilibrium relationship with the shortterm relationship, as well as error correction or velocity measuring these variables in moving towards the long-term equilibrium. In this study, the significance of a variable to another variable assessed the significance level of $5 \%$ and $10 \%$. The VECM test results are as follows: 
Avalaible online at http://journals.ums.ac.id, Permalink/DOI: 10.23917/jep.v20i1.7097

Jurnal Ekonomi Pembangunan: Kajian Masalah Ekonomi dan Pembangunan, 20 (1), 2019, 60-68

Table 6. Test Results VECM - Long Term Relationship

\begin{tabular}{ccccc}
\hline SBL(-1) & STY(-1) & BTD(-1) & HHI(-1) & C \\
\hline \multirow{2}{*}{1} & 0.328586 & 0.071695 & 0.149059 & \\
& {$[2.58022] *$} & {$[\mathbf{1 . 6 4 2 3 6 ] * *}$} & [6.11008]* & \\
\hline
\end{tabular}

Note: * Significant 5\%. ** Significant at the $10 \%$ significance level.

Source:Researcher's Analysis Using Eview Program

Cointegration Equation Model of styrene butadiene latex (SBL) pricing at lag 1 for a longterm relationship is as follows:

SBL $(-1)=69.06705+0.328586 \operatorname{STY}(-1)+$ 0.071695 BTD $(-1)+0.149059$ HHI (-1)

At the long-term relationship, SB Latex prices show a significant positive correlation with the raw material prices, which are the prices of styrene and butadiene. This is due to the reliance of SB Latex industry on both main raw materials. There are more products with more use of styrene butadiene, (Styrene/ Butadiene approaching 1.5 to 2) that are seen with the coefficient of styrene than those seen with the coefficient of butadiene. Therefore, whenever the prices of raw material increase, it would also directly trigger the price increase of Latex. SB Latex industry structure in Indonesia is a quite competitive developing oligopoly. This industry started in 1991 and there was only one producer, namely PT BASF (monopoly). However, during 1995-2010 there had been three producers, namely PT BASF, PT Dow Chemical, and PT Latexia (oligopoly).In April 2010, PT BASF Indonesia acquired PT Latexia Indonesia (duopoly). Therefore, the market share (HHI) has a positive impact on the SB Latex price.If the market structure is controlled by only one or two companies, the company(s) is able to set the price.Higher index tends to increase the market share of SB Latex prices. Further, the error correction model for styrene butadiene latex is represented by $\Delta$ (SBL), which is able to describethe short-term relationship and longterm changes as follows:
$\Delta(\mathrm{SBL})=5.0732+0.1435 \mathrm{~L} \Delta(\mathrm{SBL})-0.00348$ $\mathrm{L} \Delta$ (SUPP) -0,01344L $\Delta$ (DMD) -0,0067 L $\Delta$ (HHI) +.02206 L $\Delta$ (STY) +0,02983L $\Delta$ (BTD -0.08875 LEC $1+.00149$ LEC $2+.01044$ LEC3

\subsection{Impulse Response Function}

Impulse Response Function (IRF) is useful to show the waya variable respond to a shock about the variable itself and other endogenous variables. To conduct the IRF of Indonesian SB Latex prices in the VECM models, standard Cholesky decomposition is used. Cholesky decomposition aims to generate impulse response that depends crucially on the order (ordering) of variables in the system (Barbi, 2011). In this study, the analysis period of the SB Latex pricing as a result of theinternal variables of SB Latex industry or microeconomic variables is 36 months (three years) ahead. More results for IRF analysis can be seen as follows:

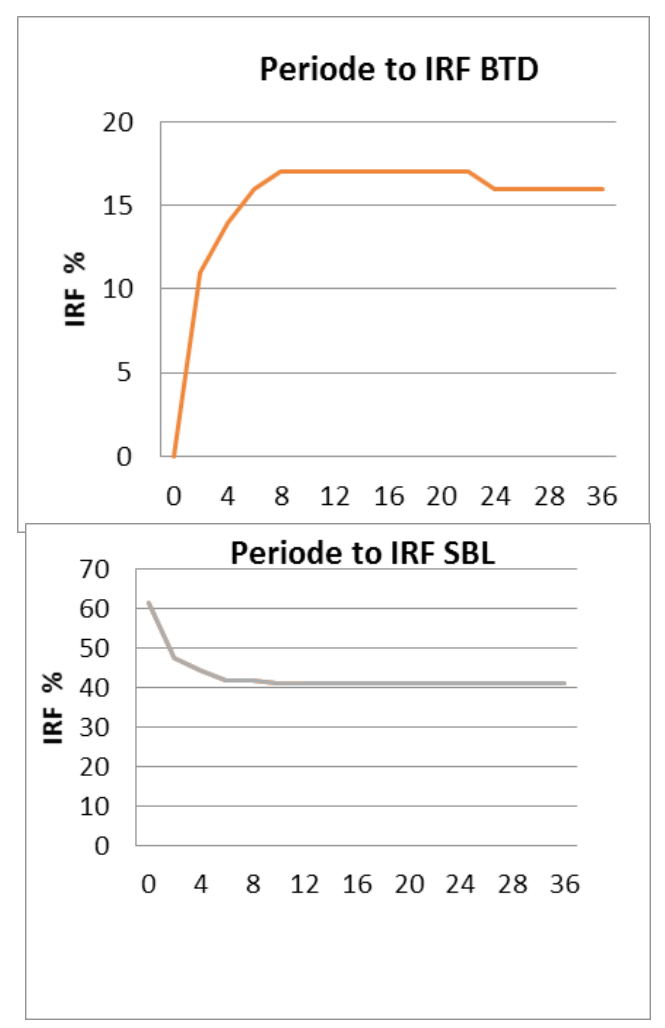

Figure 1. Results of Impulse Response Function (IRF) on theSB Latex Price

Source:Researcher's Analysis Using Eview Program.

Jurnal Ekonomi Pembangunan, ISSN 1411-6081, E-ISSN 2460-9331 


\subsection{Forecast Error Variance Decomposition} (FEVD)

The period of time used in projecting FEVD is 36 months (three years). The results are shown in Figure 2 below:
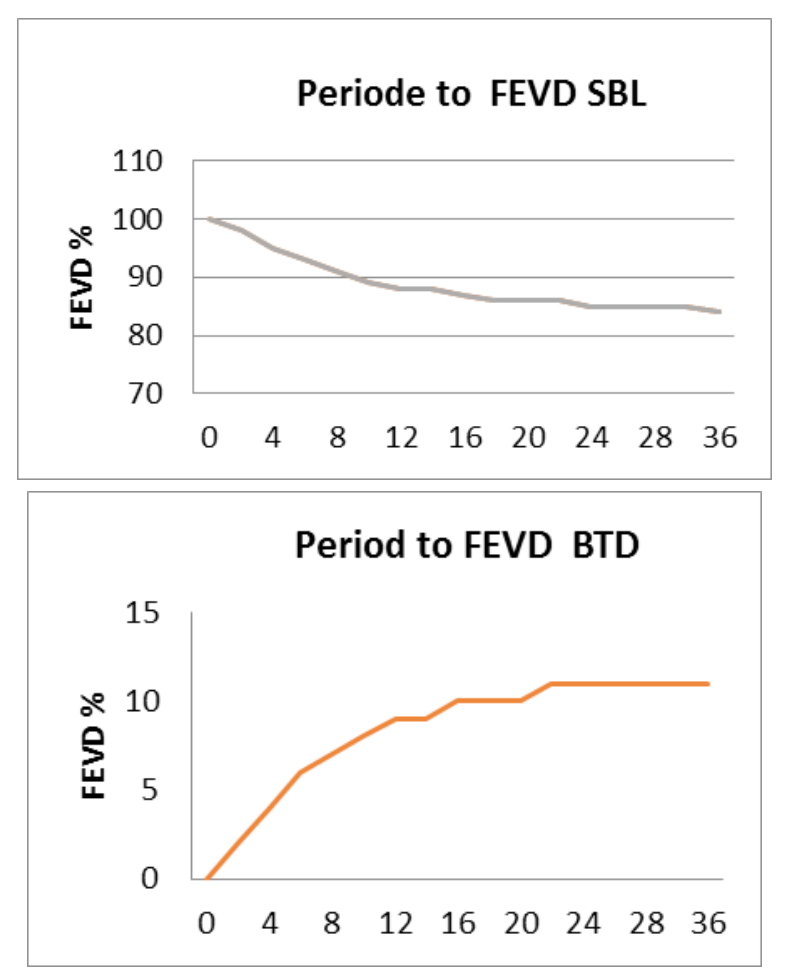

Figure 2. Forecast Error Variance

Decomposition (FEVD) on the SBL

Source:Researcher's Analysis Using Eview Program

Short-term observations (36 months) through the IRF and FEVD on the SB Latex prices show that the price variable of butadiene (BTD) is the most influential variable on SB latex pricing compared to other variables, such as SB Latex production capacity or supply, SB Latex demand, market segment index (HHI), and styrene prices. This is evident in accordance to the real occurrencein the SB Latex industry today and fifteen years back. This is due to the reliance on butadiene imports. In contrast, styrene products have been produced in Indonesia since 1995 through PT Styrindo Mono Indonesia. Therefore, almost all demands were met, mainly for styrene SB latex polystyrene industry and acrylonitrile styerene industry.In fact, the demands for butadiene had increased with an average growth of $10 \%$ from $2000-2010$, even thoughthe butadiene has not been produced in Indonesia. This triggers the price to be more expensive than the price of butadiene styrene today(CIC, 2012)

\section{Discussions}

Based on the findings of the current study, variables associated with the long-term and short-term effects on the long-term price of SB latex will have implications on the managerial SB latex as follows:

For company management, the price of raw materials (styrene and butadiene) is the main variable affecting the total manufacturing cost, which in turn will affect the company profitability. As a result,the management seeks to reduce costs through the efficiency and policies of various divisions within the company, in this case SB Latex industry in Indonesia.

Butadiene production projects carried out by PT Chandra Asri Petrochemical Centre (CAPC) with a total investment of $\$ 145$ million set off in January 2012, while production started in early 2014. This will lower the price of butadiene in Indonesia and reduce the dependence on imports, in addition to the reduction on SB Latex industrial material costs. Butadiene is used also in styrene butadiene rubber (SBR) industry and Acrylonitrile Butadiene Styrene (ABS) industry.

Competition SB Latex produce in Indonesia now only between PT BASF Indonesia with PT Dow Chemical since Ciba Speciality Chemical Corporation was acquisited by BASF The Chemical Company at 2008, so that PT Latexia Indonesia (Ciba Speciality Chemical) was eliminated to PT BASF Indonesia. Affecting to market share SB Latex in Indonesia which PT BASF Indonesia as market leader and HHI increasing almost $70 \%$ (IHS, 2018).

The price of raw materials (Styrene and Butadiene) is the main variable affecting the total manufacturing cost that will ultimately affect the company profitable, with this phenomenon. Management seek to reduce cost through efficiency programs of the various divisions 
within SB Latex industry in Indonesia (PT BASF Indonesia and PT Dow Chemical).

Industry SB Latex is an intermediate of the derivative tree industry petrochemical industry, which generally requires a steady supply, the main raw material, namely Styrene and Butadiene, where the development of the main raw material prices have a tendency to rise from year to year due to higher crude oil prices, so that should be pursued and developed process technology to reduce the use of Styrene and Butadiene, but does not reduce the quality of SB Latex in industrial applications, namely Paper Coating and Carpet. BASF The Chemical Company April 2010 have applied dextrem process to the entire plant in the worldwide through methods add starch to the polymerization process in order to reduce the use of Butadiene, and this has an impact on the selling price of SB Latex in the market.

Innovation technology in industrial SB latex process is a necessity that must be done in a sustainable manner through research and development, especially SB Latex products are shaped emulsion polymer (viscous white liquid), making it easier do modifications in process technology than for solid polymer (condensation polymer). A modified form is the first, namely the reduction of the use of reagent, the second is the reduction in the use of the main raw material, namely Styrene and Butadiene, the third is the substitution of other raw materials at cheaper prices, the fourth one is saving and substitution of energy for utilities, the fifth is the reduction of the polymerization reaction time (cycle time process). Cycle Time Process in the manufacturing SB Latex has developed gradually, starting in the early years of 1950-1970 manufacture of SB Latex takes nearly 24 hours, the period from 1971 to 1980 is shortened to 16 hours, the period from 1981 to 1990 was reduced to 12 hours, the period 1991 -2000 can be reduced again to eight hours, the period from 2001 to 2010 can be accelerated to 6 hours. Developing cycle time can not alone but always simultaneously accompanied by other process. Modification Process Technology above will have direct impact on pricing SB Latex, in order to obtain more competitive prices.

Previous study which The prices of Petrochemical Industry products in Indonesia cannot avoid the effects of globalization on the prices of Petrochemical Industry products in the global market. In more detail and in more detail petrochemical products are an inseparable part of the upstream industry, while the SB Latex Petrochemical Industry is a derivative industry from the upstream industry or often called an intermediate industry which is a supplier of industrial paper coating, carpet backing, paint, material construction and textiles. So if there is a change in SB Latex prices on the global market (SB Latex prices USA, Japan, China and Western Europe) then this will have an impact on SB Latex prices in Indonesia (Huang \& Chen, 2013).

\section{Conclusions and Suggestions.}

\subsection{Conclusions}

Domestic factors that affect SB latex prices in Indonesia are the main raw material (styrene and butadiene) prices and the market share of demands for latex and SB latex in the paper coating industry and carpet industry in Indonesia.

The short-term aspects affecting the SB Latex pricing in Indonesia is the price of SB Latex itself and demands for SB Latex by the paper coating industry and carpet industry.Meanwhile, the long-term aspects that affect the SB Latex pricing in Indonesia are the prices of main raw (styrene and butadiene) materials and the market share of SB Latex industry in Indonesia (HHI).

In terms of industrial market share of SB Latex (HHI), the prices of styrene and butadiene could contribute significantly to the changes of SB Latex prices in the long run. This contrasts to the short-term relationship between the intense manufacturer competition and the SB Latex price. Tough competition between manufacturers of SB Latex nation wide results in the price declines, although demands for SB Latex increases.

\subsection{Suggestions}

This study has alimitation that it only focuses on one derivative petrochemical product, which is 
Styrene Butadiene Latex (SBL). Therefore,further studies need to be carried out focusing onother petrochemical derived products (downstream and intermediate).

\section{References}

Barbi, T. (2011). Relationship Between Macroeconomic Fundamentals and Stock Market Indices nn Selected Cee Countries. 62, 113-133.

CIC. (2012). PT. CAPRICORN Indonesia Consult Inc. RE: Indonesia's Compilation of Chemical Business Profile 2011 - 2012. 3101081(89).

E.H. Pechan \& Associates, I. (1995). Economic Impact Analysis for the Polymers and Resins Group I. (68), 0-105. https://doi. org/10.2214/AJR.10.5157

Engle, R. F., \& Granger, C. W. J. (1987). Engle Granger_1987.pdf (pp. 251-276). pp. 251276.

Fan, J. P. H. (1998). Price Uncertainty and Vertical Integration: An Empirical Examination of Petrochemical Firms. Ssrn, 345-347. https://doi.org/10.2139/ssrn.80468

Huang, A. Y., \& Chen, C. (2013). Oil Prices and Stock Prices of Alternative Energy Companies: Time Varying Relationship with Recent Evidence.

IHS. (2018). Styrene-Butadiene Latexes. (August).

Johansen. (1990). Maximum Likelihood Estimation and Inference on Cointegration - With. Oxford Bulletin of Economics and Statistics, 2, 170-209.

Jones, D. W., Leiby, P. N., \& Paik, I. K. (2004). Oil Price Shocks and the Macroeconomy : What Has Been Learned Since 1996 Published by: International Association for Energy Economics Stable URL: http://www.jstor. org/stable/41323029 Oil Price Shocks and the Macroeconomy: Oil Price Shocks and the Macroeconomy: What Has Been Learned Since 1996, 25(2), 1-32. https://doi. org/10.2307/41323029

jorgenson. (1968). an Econometric Approach To Measures. 241(September).

Luburic, N., \& Katz, R. (2011). Competitiveness Criteria and Possible Recovery Strategies for Petrochemical Business. Business Intelligence Journal, 4(1), 79-89.

Mei, B., \& Sun, C. (2008). Assessing TimeVarying Oligopoly and Oligopsony Power in the U. S . Paper Industry. Paper Industry, 3(December), 927-939. https:// doi.org/10.1017/S107407080000242X

Nugroho, R. E, Hakim, D. B., Nurmalina, R., \& Manurung, A. H. (2011). Faktor Faktor Eksternal Yang Indonesia Faktor - Faktor Eksternal Yang Mempengaruhi Harga Styrene Butadiene Latex ( SBL ) Di Indonesia.

Nugroho, Rosalendro Eddy, Albar, D., \& Hasibuan, S. (2018). Improved Inventory Management Performance in Indonesia Spare-Parts Company Using $A B C$ Classification and Min-Max Method Saudi Journal of Business and Management Studies ( SJBMS ) Improved Inventory Management Performance in Indonesia Spare - Parts Company . (March). https:// doi.org/10.21276/sjbms.2018.3.3.6

Usman, S., \& Aliyu, R. (2009). Mp r a. Journal of African Trade, (16319).

Verbeek, M. (2008). A Guide to Modern Econometrics. In Text. https://doi. org/10.1017/CBO9781107415324.004

Wen, Y. (2007). Granger Causality and. Tellus A, 195-206.

Zhang, Q. (2011). The impact of international oil price fluctuation on China's economy. Energy Procedia, 5, 1360-1364. https://doi. org/10.1016/j.egypro.2011.03.235 